\title{
Change of hypothalamic adult neurogenesis in mice by chronic treatment of fluoxetine
}

\author{
Koji Ohira* (1)
}

\begin{abstract}
Objective: More than half of patients with depression display eating disorders, such as bulimia nervosa and anorexia nervosa. Feeding centers are located in the hypothalamus, and hypothalamic adult neurogenesis has an important role in feeding and energy balance. Antidepressants, which can regulate adult neurogenesis in the hippocampus, olfactory bulb, and neocortex, are used for eating disorders, but it is unclear whether antidepressants change hypothalamic adult neurogenesis. In this study, we used immunohistological analysis to assess effects of the antidepressant fluoxetine ( $F L X)$ on hypothalamic adult neurogenesis of adult mice.

Results: Expressions of the proliferating cell marker, Ki67, and the neural stem cell marker, nestin, were significantly decreased in the hypothalamus by FLX. As regard to postmitotic cells, the number of the neural marker, NeuN, positive cells was significantly upregulated by FLX, but that of the astrocytic marker, S100B, positive cells was significantly reduced by FLX. The number of the oligodendrocyte marker, Olig2, positive cells was not changed by FLX. Interestingly, FLX treatment did not affect the total number of newly generated cells in the hypothalamus, comparing that in controls. These results suggest that FLX treatment influence hypothalamic adult neurogenesis and shift the balance between the numbers of neurons and astrocytes under studied conditions.
\end{abstract}

Keywords: Adult neurogenesis, Antidepressant, Hypothalamus, Neural stem cell

\section{Introduction}

Many studies have demonstrated that new neurons are generated in limited regions of the adult brain, such as the hippocampal dentate gyrus (HDG), subventricular zone (SVZ), cerebral cortex, and hypothalamus [1-3]. Neural stem cells (NSCs), which can produce neuronal progenitor cells (NPCs) and glial progenitor cells, and each progenitor cell, which can produce postmitotic neurons and glial cells, are found in these regions, and can persist neurogenesis under physiological conditions, throughout life [4-6]. Although it is still controversial whether sufficient numbers of neurons are produced in these regions of adult humans [7-9], adult neurogenesis, NSCs, and

\footnotetext{
*Correspondence: kohira@mukogawa-u.ac.jp
}

Laboratory of Nutritional Brain Science, Department of Food Science

and Nutrition, Mukogawa Women's University, 6-46 Ikebiraki, Nishinomiya,

Hyogo 663-8558, Japan
NPCs are present in primates, including humans [10-12]. It is becoming increasingly clear that new neurons in the existing neural network may function in adult brains. Neurogenesis in the HDG and SVZ is related to the memory of events and odor, respectively [13]. New neurons in the cerebral cortex have neuroprotective function against brain ischemia [14].

In the past 2 decades, evidence has accumulated that neurogenesis can occur in adult mammalian hypothalamus. In the third ventricle of the hypothalamus, NSCs exist and produce new neurons. Hypothalamic NSCs, called tanycytes, are subdivided into four types, such as $\alpha 1, \alpha 2, \beta 1$, and $\beta 2$, based on their position, gene expression pattern, innervation, and neurogenic potential. The $\alpha 2$-tanycytes display neurogenic characteristics. The functions of the hypothalamus are involved in the regulation of metabolism, reproduction, endocrine, sleep, and body temperature, and new neurons in the hypothalamus 
are expected to be related to those functions. In fact, new neurons contain gonadotropin-releasing hormone, thyrotropin-releasing hormone, oxytocin, and vasopressin [15]. Recent studies have found the role of hypothalamic neurogenesis in metabolic regulation and reproductive physiology [16]. Levels of hypothalamic neurogenesis can be regulated by dietary, environmental and hormonal signals. Since the hypothalamus has a central role in controlling a broad range of homeostatic physiological processes, these findings may have far ranging behavioral and medical implications [17].

The abnormalities of adult neurogenesis in these regions have been reported to be involved in neuropsychiatric disorders, such as Alzheimer's disease and depression. There is a significant decrease in HDG neurogenesis in patients with Alzheimer's disease and some animal models [18]. Although there is no direct evidence that adult neurogenesis is decreased in patients with depression, stress, which is one of the major factors for depression, decreases adult neurogenesis in the HDG of experimental animals [19]. In addition, NSCs and NPCs in the HDG, cerebral cortex, and SVZ, are affected by antidepressants. Chronic antidepressant treatment increases neurogenesis in the HDG [20] and cerebral cortex [14], and has the opposite effect on neurogenesis in the SVZ [21].

Depression is a common mental disorder, affecting approximately 300 million people worldwide in 2017 [22]. More than $50 \%$ of patients with depression have been reported to show eating disorders [23]. For patients with eating disorders, selective serotonin reuptake inhibitors (SSRIs), a group of antidepressants, are used for drug treatment [24]. Hypothalamic neurogenesis functions as a regulator of eating behaviors and energy balance [25]. However, there are almost no data that SSRIs influence hypothalamic neurogenesis, although early exposure to SSRIs is linked to depression and anxiety-like disorders [26]. In this study, we examined whether the SSRI, fluoxetine (FLX), administration affect hypothalamic neurogenesis in adult mice, using immunohistological methods.

\section{Main text \\ Materials and methods \\ Experimental animals}

Eight adult male C57BL/6 J mice (8-week-old; Japan SLC, Shizuoka, Japan) were used in this study. Housing conditions were thermostatically maintained at $24 \pm 1{ }^{\circ} \mathrm{C}$ with constant humidity $(60 \%)$ and lighting (12 h light/dark cycle, light on: 7:00-19:00). The animals were housed for 1 week before the experiments and fed a normal diet and water given ad libitum. The experimental procedures for animals were executed in accordance with Mukogawa
Women's University's guidelines for the ethical treatment of laboratory animal.

\section{FLX and bromodeoxyuridine (BrdU) treatments}

FLX and BrdU treatments were performed as described previously [1]. Briefly, 8 mice were randomly divided into 2 groups (4 mice/group); each group of mice was intraperitoneally injected with vehicle (phosphate-buffered saline, PBS) or $15 \mathrm{mg} / \mathrm{kg}$ FLX (LKT Laboratories, St Paul, $\mathrm{MN}$ ) every day for 4 weeks. From previous studies [27, 28 ], assuming a FLX-altered cell volatility of $40-50 \%$, about 4 animals are required per group. In addition, intraperitoneal administration was performed to keep the daily FLX dose was constant. At 1 week after the onset of FLX treatment, an injection of BrdU $(100 \mathrm{mg} /$ kg; Sigma Aldrich, St. Louis, MO) was administered at 10 AM once a day for 3 consecutive days. After 4 weeks, the mice were deeply anesthetized with $3 \%$ isoflurane (Wako, Osaka, Japan), killed by bloodletting from the right atrium, and perfused with $4 \%$ paraformaldehyde (Merck, Darmstadt, Germany) in PBS. The brains were removed and immersed 4\% paraformaldehyde overnight at $4{ }^{\circ} \mathrm{C}$. Then, the brains were store in PBS containing $20 \%$ sucrose for cryoprotection until use. Body weights of mice were measured every week from the onset of the experiment. The rationale regarding the animals used in the experiment, administration method, and group size is in the Additional file 1.

\section{Immunofluorescent staining}

Immunofluorescent staining for brain sections was performed as described previously [14]. Briefly, the brains were cut into $50 \mu \mathrm{m}$-thick coronal sections using a microtome (LS-113; Yamato Kohki Industrial, Saitama, Japan). Sections were stored in PBS containing sodium azide $\left(0.05 \%\right.$, w/v) at $4{ }^{\circ} \mathrm{C}$ until use. Four mice were used to stain sections with each cell type marker antibody; proliferating cells, neurons, astrocytes, and oligodendrocytes.

For BrdU staining, sections were incubated at $4{ }^{\circ} \mathrm{C}$ for $10 \mathrm{~min}$ in $0.1 \mathrm{~N} \mathrm{HCl}$ and then at $37^{\circ} \mathrm{C}$ for $30 \mathrm{~min}$ in $2 \mathrm{~N}$ $\mathrm{HCl}$. Sections were washed twice for $5 \mathrm{~min}$ in PBS and then blocked in $0.2 \mathrm{M}$ glycine in PBS at RT for at least $2 \mathrm{~h}$. The following procedures were the same as methods with other primary antibodies.

Sections were incubated with primary antibodies overnight at RT. The list of antibodies used in the experiments is given in the Additional file 2. After washing in PBS for $30 \mathrm{~min}$, sections were incubated at RT for $1 \mathrm{~h}$ with secondary antibodies. Sections were then washed in PBS for $30 \mathrm{~min}$, mounted on glass slides coated with 3-aminopropyltriethoxysilane, and embedded with PermaFluor (Thermo Fisher Scientific, Waltham, MA, USA). 
Images were acquired by using an LSM 510 confocal laser-scanning microscope (Carl Zeiss, Oberkochen, Germany) with a pinhole setting that corresponded to a focal plane thickness of less than $1 \mu \mathrm{m}$ to obtain images of the stained sections. Quantitative analysis was performed as reported previously [14]. Quantification of positive structures was performed in a blinded manner, i.e., encoded images were assessed in random order by other investigators, although investigators could not be blinded to the groups due to breeding in the difference cages.

We examined the hypothalamic region, which approximately corresponds to -1.46 to $-2.06 \mathrm{~mm}$ posterior from bregma in the atlas of Franklin and Paxinos [29]. Approximately 12 sections from each animal (4 FLXtreated and 4 control mice) were obtained. The sections from each group were divided into 4 groups: for NSCs, for neurons, for astrocytes, and for oligodendrocytes, each of which comprised 12 sections. Positive signals were counted in the whole structures of thalamus.

\section{Data analysis}

All data are presented as mean \pm SD. GraphPad Prism (version 6, GraphPad Software, La Jolla, CA) was used to analyze all data. For all statistical analyses used, the alpha level was set at $\mathrm{P}<0.05$. Differences between FLX-treated and control groups were compared using unpaired $t$ test. There were no criteria used for including and excluding experimental units.

\section{Results}

Hypothalamic NSCs have been reported to express the NSC marker, nestin. Proliferating cells, including NSCs and NPCs, express Ki67 protein in their nuclei. First, by using these markers, we determined whether NSCs and NPCs in the hypothalamus were affected by FLX treatments. The fluorescence intensity of nestin-positive $(+)$ structures was significantly reduced by FLX treatments, compared with controls $(\mathrm{P}=0.0024)$ (Fig. $1 \mathrm{~A}-\mathrm{C})$. In addition, the number of $\mathrm{Ki}^{+} 7^{+}$cells was significantly decreased in the hypothalamus of FLX-treated mice, compared with controls $(\mathrm{P}=0.0007)$ (Fig. 1D-F). The proliferation ability of NSCs and NPCs correlates with the level of nestin expression [30]. These results suggest that chronic FLX administration down-regulates the densities of NSCs and NPCs.

Next, we determined whether the numbers of newlyproduced neurons, astrocytes, and oligodendrocytes, from NSCs were altered by FLX treatments. Contrary to expectations based on decreased densities of hypothalamic NSCs and NPCs in FLX-treated mice, we found that FLX treatments increased the density of new neurons $(P=0.0457)$, which had the neuron maker NeuN

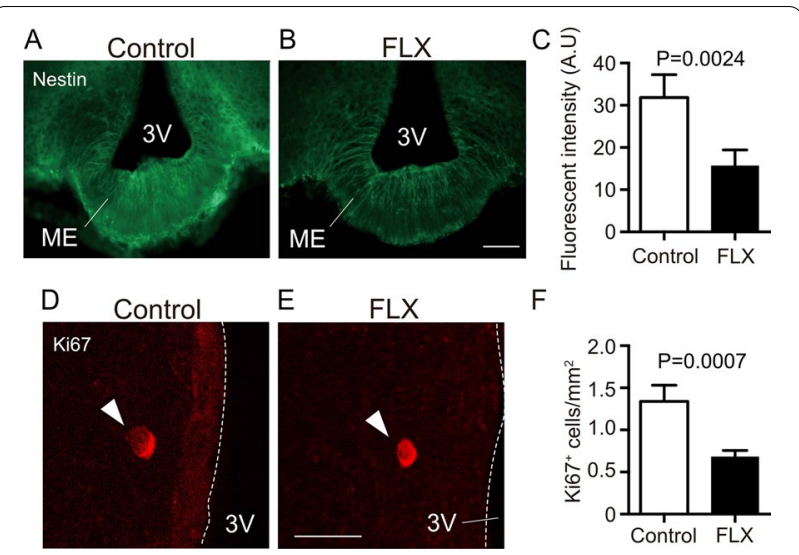

Fig. $1 \mathrm{FLX}$ treatment decreased the number of proliferating cells in the hypothalamus of adult mice. A, B Representative images of the NSC marker, nestin, positive structures in the hypothalamus of mice treated with vehicle (upper) or FLX (lower). C The fluorescence intensities of nestin-positive structure were quantified in the hypothalamus of vehicle-treated and FLX-treated mice ( $n=4$ mice each). D, E Representative images of the dividing cell marker, Ki67, positive cells in the hypothalamus of mice treated with vehicle (upper) or FLX (lower). F The number of Ki67-positive cells was quantified in the hypothalamus of vehicle-treated and FLX-treated mice ( $n=4$ mice each). Scale bar, $100 \mu \mathrm{m}$ in $\mathbf{A}$ and $\mathbf{B}, 20 \mu \mathrm{m}$ in $\mathbf{D}$ and E. $3 V$ third ventricle; ME medial eminence. Values (mean \pm SD) are analyzed by Student's t test

and the cell proliferation marker BrdU, in the hypothalamus (Fig. 2A, B). On the other hand, the density of newlygenerated astrocytes, which were the astrocyte marker $\mathrm{S} 100 \mathrm{~B}^{+}$and $\mathrm{BrdU}^{+}$cells, was significantly reduced by FLX treatments $\left(\mathrm{P}=1.75 \times 10^{-5}\right)$, compared with controls (Fig. 2C, D). As for oligodendrocytes, which were the oligodendrocyte marker Olig2 ${ }^{+}$and $\mathrm{BrdU}^{+}$cells, there was little change in the numbers between FLXtreated and control mice $(\mathrm{P}=0.119)$ (Fig. 2E, F). The percentage of each cell type (neurons, astrocytes, and oligodendrocytes) in both groups at 4 weeks after vehicle or FLX treatment is shown in Fig. 3. The numbers of total newly-generated cells were not changed between both groups $(\mathrm{P}=0.167)$ (Fig. 3).

\section{Discussion}

Chronic treatments with FLX have been reported to regulate adult neurogenesis: up-regulation in the hippocampus [20], cortex [14], and hypothalamus [27], and down-regulation in the olfactory bulb [21]. These findings suggest that chronic treatments with FLX affect the behaviors of NSCs and NPCs in adult brains. In this study, the experimental data indicate that treatment for 4 weeks with FLX decreased the densities of NSCs and NPCs in the hypothalamus. As mechanisms of this phenomenon, it would be assumed that the expressions 


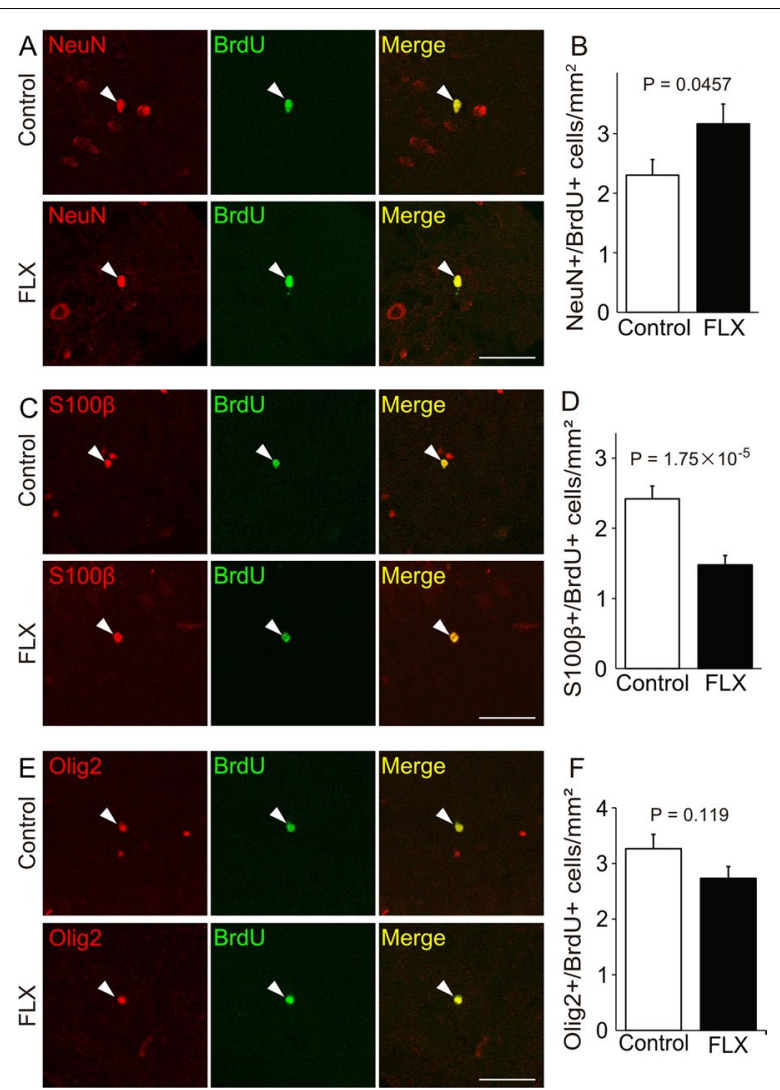

Fig. 2 Changes of the numbers of newly-generated cells in the hypothalamus of adult mice. A, B Images of the neuron marker, NeuN (green) and the proliferating cell marker, BrdU (red), double-positive cells. The quantification of the number of NeuN/BrdU-positive cells is shown. C, D Images of the astrocyte marker, S100 $\beta$ (green) and $\mathrm{BrdU}$ (red) double-positive cells. The quantification of the number of $\mathrm{S} 100 \beta / \mathrm{BrdU}$-positive cells is shown. $(\mathrm{E}, \mathrm{F})$ Images of the oligodendrocyte marker, Olig2 (green) and BrdU (red) double-positive cells. The quantification of the number of Olig2/BrdU-positive cells is shown ( $n=4$ mice each). Arrowheads indicate the same cells. Scale bar, $50 \mu \mathrm{m}$ in $\mathbf{A}, \mathbf{C}$, and $\mathbf{E}$. Values (mean \pm SD) are analyzed by Student's t test

of 5-HT receptor subtypes in NSCs and NPCs might be different among them [31-35], and the direction of adult neurogenesis might be determined by the expression levels, balance of receptor subtypes, and the status of intracellular signaling cascades.

In this study, I found that the number of total newlygenerated cells was not changed, even though the numbers of NSCs and NPCs were decreased by FLX. The proliferation ability of NSCs and NPCs correlates with the level of nestin expression [30], indicating that the numbers of NSCs and NPCs in the hypothalamus are decreased by FLX. In addition, FLX increased the number of new neurons, decreased that of new astrocytes and did not change that of oligodendrocytes in the

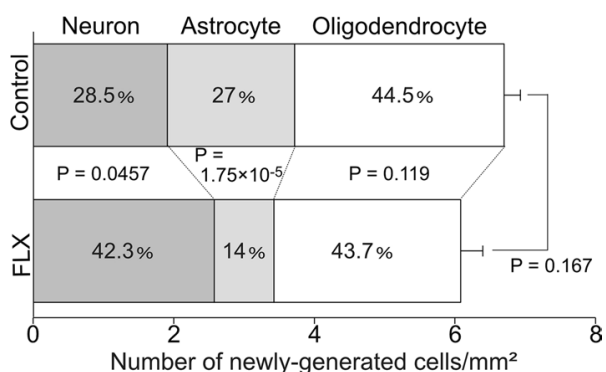

Fig. 3 Comparison of total number of newly-generated cells in FLX-treated and control mice. The numbers of new neurons and astrocytes were changed by FLX, but that of oligodendrocytes was not changed. These numbers of neurons, astrocytes, and oligodendrocytes were the same as in Fig. 2. The total number of newly-generated cells was almost unchanged, compared with both groups ( $n=4$ mice each). Values (mean $\pm S D$ ) are analyzed by Student's t test

hypothalamus. It is conceivable that the increased number of new cells might be due to the longer survival of the cells after division. FLX up-regulates the expression of BDNF in the hypothalamus [27, 36]. BDNF can promote the survival of neurons and oligodendrocytes in the spinal cord [37, 38]. As for astrocytes, FLX upregulates BDNF expression in astrocytes [39], but it remains unclear whether BDNF can increase the survival of astrocytes [40]. Thus, these findings suggest that FLX increases the expression of BDNF, which might promote the survival of new neurons and oligodendrocytes in the hypothalamus. As a result, even though the numbers of NSCs and NPCs are decreased by FLX, the number of total newly-produced cells has not changed. Another possibility is that FLX would promote differentiation into neurons. This action might have reduced the number of NSCs and NPCs, increased that of neurons, and reduced that of astrocytes. However, the findings are the opposite of the findings of previous in vitro evidence [41]. This might reflect the difference between in vitro and in vivo experiments. Further analysis of the effect of FLX on adult neurogenesis in the thalamus is needed, including its relationship to depression and eating disorders (a discussion about depression and eating disorders can be found in Additional file 1).

\section{Limitations}

Although it is relevant to understand how FLX treatment administered to naive control mice affects hypothalamic adult neurogenesis, it is much more important to understand the effect of fluoxetine treatment in depressive models or in animal models of eating disorders. In this study, we performed a quantitative analysis of positive cells and structures by fluorescent intensity. However, 
since the fluorescence intensity varies slightly between experiments, we made efforts to reduce the variation by experimenting with one sample three times. We also claim from indirect data that new cell numbers have not changed despite FLX treatment. In the future, it will be necessary to perform double staining of BrdU and nuclear staining to directly count new cell numbers.

\section{Abbreviations}

BrdU: Bromodeoxyuridine; FLX: Fluoxetine; NPC: Neural progenitor cell; NSC: Neural stem cell; PBS: Phosphate-buffered saline.

\section{Supplementary Information}

The online version contains supplementary material available at https://doi. org/10.1186/s13104-022-05954-z.

Additional file 1: 1. Rationale and discussion of methodology. 2. Discussion of hypothalamic neurogenesis, antidepressants, and their relationship to depression and eating disorders.

Additional file 2. Antibodies.

\section{Acknowledgements}

I would like to thank Saki Okamoto, Chihiro Takada, Yuki Asai, and Fuko Kadono for their experimental supports, including injection of PBS or FLX solution, cutting brain slices, immunostaining, capturing tissue images, and quantification of positive structures.

\section{Authors' contributions}

$\mathrm{KO}$ conceived the study, analyzed the data, and wrote the manuscript. The author read and approved the final manuscript.

\section{Funding}

This research was supported by JSPS KAKENHI Grant Number JP 20 K06903.

\section{Availability of data and materials}

The datasets used during this study are available from the corresponding author upon reasonable request.

\section{Declarations}

\section{Ethics approval and consent to participate}

Our study was approved in 2016 by the Institutional Ethics Committee of Mukogawa Women's University (FSN-03-2016-01-P; date of approval: July 24, 2016).

\section{Consent for publication}

Not applicable.

\section{Competing interests}

The author declares that he has no competing interests.

Received: 3 December 2021 Accepted: 4 February 2022 Published online: 16 February 2022

\section{References}

1. Ohira K. Injury-induced neurogenesis in the mammalian forebrain. Cell Mol Life Sci. 2011;68:1645-56.

2. Yoo S, Blackshaw S. Regulation and function of neurogenesis in the adult mammalian hypothalamus. Prog Neurobiol. 2018;170:53-66.
3. Obernier K, Alvarez-Buylla A. Neural stem cells: origin, heterogeneity and regulation in the adult mammalian brain. Development. 2019. https:// doi.org/10.1242/dev.156059.

4. Cameron HA, Woolley CS, McEwen BS, Gould E. Differentiation of newly born neurons and glia in the dentate gyrus of the adult rat. Neuroscience. 1993;56:337-44.

5. Lois C, Alvarez-Buylla A. Proliferating subventricular zone cells in the adult mammalian forebrain can differentiate into neurons and glia. Proc Natl Acad Sci USA. 1993:90:2074-7.

6. Ohira K, Furuta T, Hioki H, Nakamura KC, Kuramoto E, Tanaka Y, et al. Ischemia-induced neurogenesis of neocortical layer 1 progenitor cells. Nat Neurosci. 2010;13:173-9.

7. Sorrells SF, Paredes MF, Cebrian-Silla A, Sandoval K, Qi D, Kelley KW, et al. Human hippocampal neurogenesis drops sharply in children to undetectable levels in adults. Nature. 2018;555:377-81.

8. Boldrini M, Fulmore CA, Tartt AN, Simeon LR, Pavlova I, Poposka V, et al. Human hippocampal neurogenesis persists throughout aging. Cell Stem Cell. 2018:22:589-599.e5.

9. Hagihara H, Murano T, Ohira K, Miwa M, Nakamura K, Miyakawa T. Expression of progenitor cell/immature neuron markers does not present definitive evidence for adult neurogenesis. Mol Brain. 2019;12:108.

10. Eriksson PS, Perfilieva E, Björk-Eriksson T, Alborn AM, Nordborg C, Peterson $D A$, et al. Neurogenesis in the adult human hippocampus. Nat Med. 1998:4:1313-7.

11. Curtis MA, Penney EB, Pearson AG, van Roon-Mom WMC, Butterworth $\mathrm{NJ}$, Dragunow M, et al. Increased cell proliferation and neurogenesis in the adult human Huntington's disease brain. Proc Natl Acad Sci USA. 2003;100:9023-7.

12. Ohira K, Hagihara H, Miwa M, Nakamura K, Miyakawa T. Fluoxetineinduced dematuration of hippocampal neurons and adult cortical neurogenesis in the common marmoset. Mol Brain. 2019;12:69.

13. Imayoshi I, Sakamoto M, Ohtsuka T, Takao K, Miyakawa T, Yamaguchi M, et al. Roles of continuous neurogenesis in the structural and functional integrity of the adult forebrain. Nat Neurosci. 2008;11:1153-61.

14. Ohira K, Takeuchi R, Shoji H, Miyakawa T. Fluoxetine-induced cortical adult neurogenesis. Neuropsychopharmacology. 2013;38:909-20.

15. Markakis EA, Palmer TD, Randolph-Moore L, Rakic P, Gage FH. Novel neuronal phenotypes from neural progenitor cells. J Neurosci. 2004;24:2886-97.

16. Jurkowski MP, Bettio L, Woo EK, Patten A, Yau S-Y, Gil-Mohapel J. Beyond the hippocampus and the SVZ: adult neurogenesis throughout the brain. Front Cell Neurosci. 2020. https://doi.org/10.3389/fncel.2020.576444.

17. Kokoeva MV, Yin H, Flier JS. Neurogenesis in the hypothalamus of adult mice: potential role in energy balance. Science. 2005;310:679-83.

18. Dard RF, Dahan L, Rampon C. Targeting hippocampal adult neurogenesis using transcription factors to reduce Alzheimer's disease-associated memory impairments. Hippocampus. 2019;29:579-86.

19. Czeh B, Simon M, van der Hart MG, Schmelting B, Hesselink MB, Fuchs E. Chronic stress decreases the number of parvalbumin-immunoreactive interneurons in the hippocampus: prevention by treatment with a substance P receptor (NK1) antagonist. Neuropsychopharmacology. 2005;30:67-79.

20. Malberg JE, Eisch AJ, Nestler EJ, Duman RS. Chronic antidepressant treatment increases neurogenesis in adult rat hippocampus. J Neurosci. 2000;20:9104-10.

21. Ohira K, Miyakawa T. Chronic treatment with fluoxetine for more than 6 weeks decreases neurogenesis in the subventricular zone of adult mice. Mol Brain. 2011;4:10.

22. Mishra A, Galhotra A. Mental Healthcare Act 2017: need to Wait and Watch. Int J Appl Basic Med Res. 2018:8:67-70.

23. American Psychiatric Association Work Group on Eating Disorders. Practice guideline for the treatment of patients with eating disorders (revision). Am J Psychiatry. 2000;157(1 Suppl):1-39.

24. Himmerich $\mathrm{H}$, Treasure J. Psychopharmacological advances in eating disorders. Expert Rev Clin Pharmacol. 2018;1 1:95-108.

25. Sousa-Ferreira L, de Almeida LP, Cavadas C. Role of hypothalamic neurogenesis in feeding regulation. Trends Endocrinol Metab. 2014;25:80-8.

26. Henry LK, Rodriquez MA, Allen MD, Shetty M, Perley D. Fluoxetine and citalopram significantly alter gene expression in the midbrain of neonate mice uncovering possible antidepressant-mediated epigenetic programming changes during development. FASEB J. 2018;32:787.19-787.19. 
27. Sachs BD, Caron MG. Chronic fluoxetine increases extra-hippocampal neurogenesis in adult mice. Int J Neuropsychopharmacol. 2014. https:// doi.org/10.1093/ijnp/pyu029.

28. Dulawa SC, Holick KA, Gundersen B, Hen R. Effects of chronic fluoxetine in animal models of anxiety and depression. Neuropsychopharmacology. 2004;29:1321-30.

29. Paxinos G, Franklin KBJ. The mouse brain in stereotaxic coordinates. Houston: Gulf Professional Publishing; 2004.

30. Kawaguchi A, Miyata T, Sawamoto K, Takashita N, Murayama A, Akamatsu W, et al. Nestin-EGFP transgenic mice: visualization of the self-renewal and multipotency of CNS stem cells. Mol Cell Neurosci. 2001;17:259-73.

31. Cubero J, Otalora BB, Bravo R, Sanchez CL, Franco L, Uguz AC, et al. Distribution of $5-\mathrm{HT}$ receptors in the mammalian brain. Trends Cell Mol Biol. 2011;6:41-6.

32. Banasr M, Hery M, Printemps R, Daszuta A. Serotonin-induced increases in adult cell proliferation and neurogenesis are mediated through different and common 5-HT receptor subtypes in the dentate gyrus and the subventricular zone. Neuropsychopharmacology. 2004;29:450-60.

33. Barnes NM, Sharp T. A review of central 5-HT receptors and their function. Neuropharmacology. 1999;38:1083-152.

34. Soumier A, Banasr M, Kerkerian-Le Goff L, Daszuta A. Region- and phasedependent effects of $5-\mathrm{HT}(1 \mathrm{~A})$ and $5-\mathrm{HT}(2 \mathrm{C})$ receptor activation on adult neurogenesis. Eur Neuropsychopharmacol. 2010;20:336-45.

35. Klempin F, Babu H, De Tonelli DP, Alarcon E, Fabel K, Kempermann G. Oppositional effects of serotonin receptors 5-HT1a, 2, and 2c in the regulation of adult hippocampal neurogenesis. Front Mol Neurosci. 2010. https://doi.org/10.3389/fnmol.2010.00014.

36. Scabia G, Barone I, Mainardi M, Ceccarini G, Scali M, Buzzigoli E, et al. The antidepressant fluoxetine acts on energy balance and leptin sensitivity via BDNF. Sci Rep. 2018;8:1781.

37. Koda M, Murakami M, Ino H, Yoshinaga K, Ikeda O, Hashimoto M, et al. Brain-derived neurotrophic factor suppresses delayed apoptosis of oligodendrocytes after spinal cord injury in rats. J Neurotrauma. 2002;19:777-85.

38. Nakajima H, Uchida K, Yayama T, Kobayashi S, Guerrero AR, Furukawa S, et al. Targeted retrograde gene delivery of brain-derived neurotrophic factor suppresses apoptosis of neurons and oligodendroglia after spinal cord injury in rats. Spine. 2010;35:497-504.

39. Allaman I, Fiumelli H, Magistretti PJ, Martin J-L. Fluoxetine regulates the expression of neurotrophic/growth factors and glucose metabolism in astrocytes. Psychopharmacology. 2011;216:75-84.

40. Cabezas R, Baez-Jurado E, Hidalgo-Lanussa O, Echeverria V, Ashrad GM, Sahebkar A, et al. Growth factors and neuroglobin in astrocyte protection against neurodegeneration and oxidative stress. Mol Neurobiol. 2019;56:2339-51.

41. Sousa-Ferreira L, Aveleira C, Botelho M, Álvaro AR, de Almeida LP, Cavadas C. Fluoxetine induces proliferation and inhibits differentiation of hypothalamic neuroprogenitor cells in vitro. PLoS ONE. 2014;9:e88917.

\section{Publisher's Note}

Springer Nature remains neutral with regard to jurisdictional claims in published maps and institutional affiliations.

Ready to submit your research? Choose BMC and benefit from:

- fast, convenient online submission

- thorough peer review by experienced researchers in your field

- rapid publication on acceptance

- support for research data, including large and complex data types

- gold Open Access which fosters wider collaboration and increased citations

- maximum visibility for your research: over $100 \mathrm{M}$ website views per year

At BMC, research is always in progress.

Learn more biomedcentral.com/submissions 